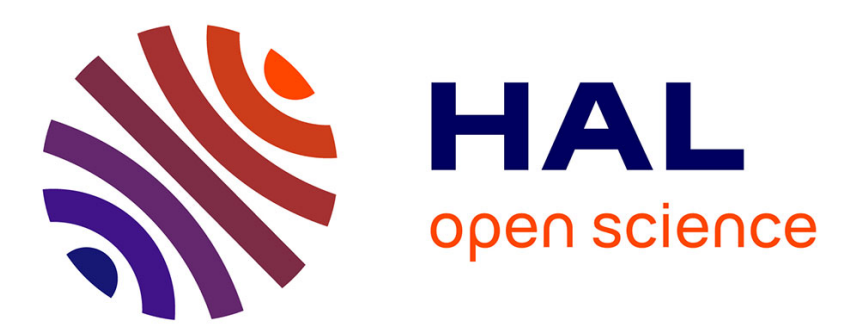

\title{
A solid-state NMR study of C70: a model molecule for amorphous carbons
}

\author{
M. Deschamps, S. Cadars, E. Gilbert, P. Azaïs, E. Raymundo-Pinero, F.
} Béguin, D. Massiot

\section{- To cite this version:}

M. Deschamps, S. Cadars, E. Gilbert, P. Azaïs, E. Raymundo-Pinero, et al.. A solid-state NMR study of C70: a model molecule for amorphous carbons. Solid State Nuclear Magnetic Resonance, 2012, 42, pp.81-86. 10.1016/j.ssnmr.2012.01.001 . hal-00620707

\section{HAL Id: hal-00620707 https://hal.science/hal-00620707}

Submitted on 8 Sep 2011

HAL is a multi-disciplinary open access archive for the deposit and dissemination of scientific research documents, whether they are published or not. The documents may come from teaching and research institutions in France or abroad, or from public or private research centers.
L'archive ouverte pluridisciplinaire HAL, est destinée au dépôt et à la diffusion de documents scientifiques de niveau recherche, publiés ou non, émanant des établissements d'enseignement et de recherche français ou étrangers, des laboratoires publics ou privés. 


\title{
A solid-state NMR study of $\mathrm{C}_{70}$ : a model molecule for amorphous carbons.
}

\author{
Michaël Deschamps, ${ }^{1,2}$ Sylvian Cadars, ${ }^{1,2}$ Edouard Gilbert, ${ }^{2,3}$ Philippe Azaïs, ${ }^{4}$ Encarnacion \\ Raymundo-Pinero, ${ }^{2,3}$ François Béguin,, ${ }^{2,3}$ Dominique Massiot ${ }^{1,2}$ \\ ${ }^{1}$ CNRS-CEMHTI, UPR 3079, 1D Avenue de la Recherche Scientifique, 45071 Orléans cedex 2, France. \\ 2 Département de Chimie, Université d’Orléans, Avenue du Parc Floral, BP 6749, 45067 Orléans cedex 2, \\ France \\ ${ }^{3}$ CNRS-CRMD, 1B rue de la Férollerie, 45071 Orléans cedex 2, France \\ ${ }^{4}$ Batscap, Odet Ergué Gabéric, 29556 Quimper cedex 9, France
}

Submitted to Solid-State NMR, special issue

Date: Friday, September 2, 2011

\begin{abstract}
We show that natural abundance, solid-state MAS-NMR ${ }^{13} \mathrm{C}$ INADEQUATE spectra can be recorded for crystallized $\mathrm{C}_{70}$, using the through-bond J-coupling for the magnetization transfer. The effect of strong J-coupling can be lessened at high magnetic fields, allowing the observation of cross-peaks between close resonances. DFT calculations of the chemical shifts show an excellent agreement with the experimental values. A correlation is observed between the average CCC bond angles and the ${ }^{13} \mathrm{C}$ chemical shift, offering a way to understand the dispersion of ${ }^{13} \mathrm{C}$ chemical shifts in nanoporous activated carbons in terms of local deviations from planarity.
\end{abstract}

\section{Introduction}

Electrochemical double-layer capacitors are made of porous carbon electrodes containing an electrolyte. Upon charging, the electronic charges are stored on the carbon electrode surface while the electrolyte structure is reorganized to maintain local electroneutrality.

The carbon materials used for the electrodes, including materials originating from biomass, such as coconut shells, have been shown to have a large impact on the energy and power densities, which can be obtained in supercapacitors. Recent research using more sophisticated materials such as curved graphene sheets ${ }^{1,2,3,4}$ or nanotubes $5,6,7,8$ have shown that these carbon structures can be used as electrode materials and provide very promising strategies for the electrochemical storage of energy.
However, little is known concerning the interplay between the carbon atomic structure and the repartition of electronic charges on the carbon surface. The molecules of the fullerenes family may be interesting models for the understanding of more complicated carbon structures. First, it has been shown that the charge distribution in $\mathrm{C}_{70}{ }^{6-}$ is not uniform and is concentrated near the poles of the $\mathrm{C}_{70}$ molecule (Figure 1A) and the presence of electronic charges mainly affects fivemembers rings. ${ }^{9}$ Second, the ${ }^{13} \mathrm{C}$ chemical shifts have been shown to depend upon the local curvature of the fullerene molecule ${ }^{10,11}$ and upon the local charge density when anions ${ }^{9}$ or cations $^{12}$ are considered. 


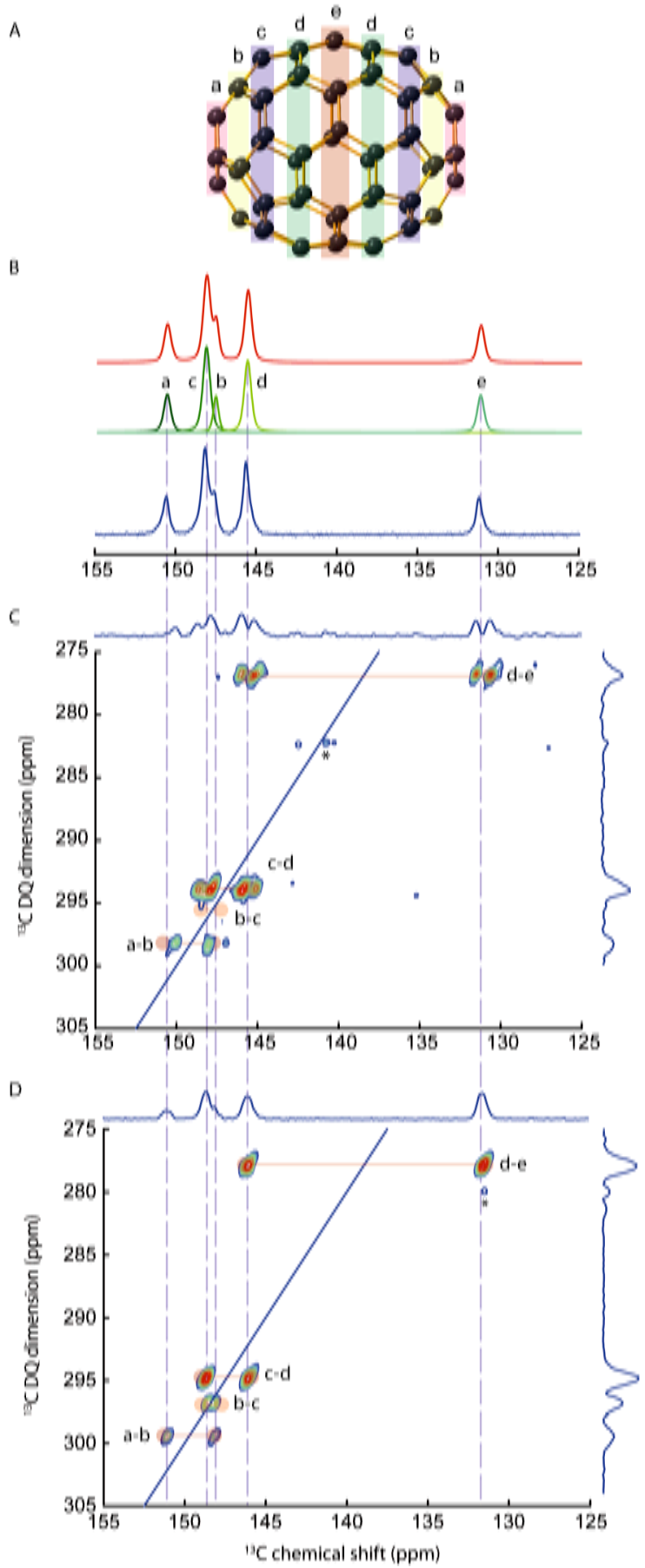

Figure 1. A: $\mathrm{C}_{70}$ molecule showing the five classes of equivalent carbon atoms in the room-temperature structure where $\mathrm{C}_{70}$ rotates along one of the symmetry axis. B: $1 \mathrm{D}$ quantitative ${ }^{13} \mathrm{C}$ solid-state NMR spectrum of $\mathrm{C}_{70}$ (blue), recorded at $7 \mathrm{~T}$, with the 5 corresponding resonances (green) and the resulting model (red). The results of the fit are shown in Table S2 of the Supplementary Material section. C: DoubleQuantum/Single-Quantum natural abundance ${ }^{13} \mathrm{C}$ refocused INADEQUATE spectrum recorded at $7 \mathrm{~T}$, showing the expected pairs of cross-peaks (red) and the missing pair $b-c$, which vanishes because of the strong coupling effect (the J-coupling and the chemical shift difference between the coupled spins are of the same order). The star $\left({ }^{*}\right)$ indicates zero-quantum (ZQ) artifacts. D: the same spectrum, recorded at $20 \mathrm{~T}$, showing all the expected pairs of cross-peaks, including the b-c cross-peaks. Again, ZQ artifacts are observed $(*)$.

In order to assign the ${ }^{13} \mathrm{C}$ NMR resonances of fullerenes, INADEQUATE spectra have been recorded using ${ }^{13} \mathrm{C}$ enriched samples since the low ${ }^{13} \mathrm{C}$ natural abundance $(1.07 \%)$ makes the probability of finding naturally occurring ${ }^{13} \mathrm{C}-{ }^{13} \mathrm{C}$ pairs quite low. ${ }^{13,9}$ Otherwise, $a b$ initio calculations have been performed to assign the observed lines in ${ }^{13} \mathrm{C},{ }^{3} \mathrm{He}$ or ${ }^{7} \mathrm{Li} \mathrm{NMR} .{ }^{14,15} \mathrm{NMR}$ has also been used for the characterization of more complicated molecules of the same family such as $\mathrm{C}_{80}{ }^{16}$ To probe the magnetic properties of fullerene molecules, ${ }^{3} \mathrm{He}$ NMR on $\mathrm{He} @ \mathrm{C}_{70}$ complexes where the $\mathrm{He}$ atoms are located inside the $\mathrm{C}_{70} 17,18$ has been successfully used, while the surface properties have been characterized using ${ }^{1} \mathrm{H}$ and ${ }^{13} \mathrm{C}$ NMR of surface groups grafted on reduced $\mathrm{C}_{70}$ molecules. ${ }^{19}$

Crystallized solvated $\mathrm{C}_{70}$ molecules have also been studied by solid-state NMR using ${ }^{1} \mathrm{H}-{ }^{13} \mathrm{C}$ cross-polarization to enhance the ${ }^{13} \mathrm{C}$ signal. ${ }^{20}$ In the solidstate, pure $\mathrm{C}_{70}$ molecules have been shown to rotate freely around their symmetry axis at room temperature using longitudinal relaxation $\left(\mathrm{T}_{1}\right)$ and Chemical Shift Anisotropy (CSA) considerations. ${ }^{21}$

In this paper, we show for the first time that natural-abundance ${ }^{13} \mathrm{C}$ INADEQUATE solid-state NMR spectra can be recorded for $\mathrm{C}_{70}$ samples, using the J-couplings between naturally occurring pairs for magnetization transfer. The 2D INADEQUATE can be recorded at "low" magnetic fields ( $7 \mathrm{~T}$ or $300 \mathrm{MHz}$ for ${ }^{1} \mathrm{H}$ ) where the line widths are narrower (in $\mathrm{Hz}$ ) and the J-splittings can be resolved. However, the $\mathrm{T}_{1}$ values are longer at low fields, and the strong J-coupling effect between two close resonances additionally leads to vanishing crosspeaks. ${ }^{22}$ At higher magnetic fields $(20 \mathrm{~T}$ 
or $850 \mathrm{MHz}$ for ${ }^{1} \mathrm{H}$ ), the Boltzmann population difference is enhanced, the longitudinal relaxation is faster, and the strong J-coupling effects are lessened even if the broader line widths (in $\mathrm{Hz}$ ) preclude the direct observation of $\mathrm{J}$ splittings.

The ${ }^{13} \mathrm{C}$ chemical shifts can be calculated using a DFT approach. The calculated values show an excellent agreement with the experimental measurements. The ${ }^{13} \mathrm{C}$ chemical shifts of these carbons (experimental and calculated) are shown to correlate with the average bond angles with the three neighboring carbons. The presence of a broad contribution between 140 and 160 ppm in the ${ }^{13} \mathrm{C}$ NMR spectra of nanoporous amorphous activated carbons can be explained by the presence of carbon atoms with smaller CCC angles in regions of higher carbon surface curvatures.

\section{Experimental NMR}

The solid $\mathrm{C}_{70}$ powder have been purchased from Sigma-Aldrich and used as is, without further purification. The supercapacitor electrode was provided by Batscap and was obtained from carbonized and activated coconut shell, with a PVDF binder and carbon black additive for conductivity. The carbon powders have been placed in a $4 \mathrm{~mm}$ Bruker $\mathrm{ZrO}_{2}$ rotor. The NMR spectra have been obtained with Bruker NMR spectrometers operating at 7 and $20 \mathrm{~T}$, corresponding to Larmor frequencies of 75.5 and $213.8 \mathrm{MHz}$ for ${ }^{13} \mathrm{C}$ (300 and $850 \mathrm{MHz}$ for ${ }^{1} \mathrm{H}$ ), using Magic Angle Spinning (MAS) rates of 10.000 and $14.286 \mathrm{kHz}$ in Bruker double resonance MAS-NMR probes. The ${ }^{13} \mathrm{C}$ chemical shifts are referenced to TMS at $0 \mathrm{ppm}$. The longitudinal relaxation times for $\mathrm{C}_{70}$ have been found to range between 2.6 and $2.9 \mathrm{~s}$ at $7 \mathrm{~T}$, and 1.6 to $2 \mathrm{~s}$ at $20 \mathrm{~T}$. The recovery delays have been set to $5 \mathrm{xT}_{1}$ for the quantitative 1D spectra and 3 and $2.4 \mathrm{~s}$ to obtain the best signal-to- noise ratio in the INADEQUATE spectra. The ${ }^{1 D}{ }^{13} \mathrm{C}$ MAS-NMR spectrum of the supercapacitor electrode was recorded with a recovery delay of $60 \mathrm{~s}$ (due to the slower longitudinal relaxation of PVDF, compared to $\mathrm{T}_{1} \leq 5 \mathrm{~s}$ for the disordered nanoporous carbon). The $90^{\circ}$ excitation pulses have been performed using $B_{1} R F$ fields of 68 and $50 \mathrm{kHz}$ respectively, and trains of eight $90^{\circ}$ pulses $20 \mathrm{~ms}$ apart were used for presaturation. The INADEQUATE spectra were recorded using a refocused INADEQUATE sequence, followed by a $20 \mathrm{~ms}$ Z-filter to obtain a pure phase spectrum. ${ }^{23} 2048$ transients have been recorded for each natural-abundance ${ }^{13} \mathrm{C}$ INADEQUATE, using conversion and reconversion delays of $8.2 \mathrm{~ms}(\approx 1 / 2 \mathrm{~J})$ to allow for the build-up of antiphase magnetization considering that ${ }^{2} \mathrm{~J}\left({ }^{13} \mathrm{C}-{ }^{13} \mathrm{C}\right) \approx 60 \mathrm{~Hz}$. In the indirect dimension, spectral widths of 2000 and $7143 \mathrm{~Hz}$ have been recorded using 100 and 50 increments at 7 and $20 \mathrm{~T}$, respectively. The experiments lasted 7 and 3 days, respectively. Single component baseline corrections and exponential broadenings of 20 and $100 \mathrm{~Hz}$ have been applied on the INADEQUATE spectra in both dimensions. The 1D spectra and the INADEQUATE slices have been fitted and/or extracted using the dmfit software. ${ }^{24}$ The simulations showing the strong J-coupling effects were performed using SPINEVOLUTION. ${ }^{25}$

\section{DFT}

First principles calculations with periodic boundary conditions were achieved using the CASTEP code, ${ }^{26,27}$ which relies on a plane-wave-based density functional theory (DFT) approach. The electron correlation effects are modeled using the PerdewBurke-Ernzerhof (PBE) generalized gradient approximation (GGA). ${ }^{28}$ For geometry optimizations we employed a planewave cut-off energy of $450 \mathrm{eV}$ and the default "ultrasoft"29 pseudo- 
potentials of CASTEP 5.5 (described in Supporting Information, Table S1). Convergence thresholds were set to $10^{-5}$ $\mathrm{eV} /$ atom for the total energy, $3.10^{-2}$ $\mathrm{eV} / \AA$ f for the maximum ionic force, and $10^{-3} \AA$ for the maximum ionic displacement. Weak non-bonding forces, which are generally absent in DFT calculations and yet crucial in the description of $\pi-\pi$ interactions, for example, were accounted for here by the damped atom-pairwise semi-empirical dispersion corrections of Tkatchenko and Scheffler. ${ }^{30}$ The NMR calculations were performed using the Gauge Including Projector Augmented Wave approach (GIPAW), ${ }^{31,32}$ at the same cutoff energy of $450 \mathrm{eV}$.

The crystal structure of $\mathrm{C}_{70}$ was previously determined by diffraction. ${ }^{33}$ For gas-phase calculations on isolated $\mathrm{C}_{70}$, one of the four $\mathrm{C}_{70}$ molecules was put in a cell of $15 \times 15 \times 15 \AA^{3}$ to avoid inter-molecular interactions, with a $2 \times 2 \times 2$ Monkhorst-Pack (MP) grid $^{34}$ to sample the Brillouin zone. The solidstate calculations were conducted with and without the symmetries of the Pbmn (\#62) space group, with unit cell parameters $\mathrm{a}=10.016 \AA, \mathrm{b}=17.349 \AA$, c $=18.530 \AA$, and $\alpha=\beta=\gamma=90^{\circ}$ kept fixed during geometry optimizations, and a 2x1x1 MP grid. An internal reference was used to calculate chemical shifts using the expression $\delta_{\text {calc }}=\sigma_{\text {ref }}-\sigma_{\text {calc }}+$ $\delta_{\text {ref, }}$ where $\sigma_{\text {ref }}$ is the average of all calculated shieldings for a given calculation, and $\delta_{\text {ref }}$ the corresponding average of all experimental ${ }^{13} \mathrm{C}$ shifts of $\mathrm{C}_{70}$ (weighed by populations) with respect to TMS.

\section{Results and discussion}

Although the low-temperature XRD structure of crystallized $\mathrm{C}_{70}$ shows 40 inequivalent sites, ${ }^{33}$ rotation about the polar axis ${ }^{21}$ at room temperature reduces the number of inequivalent sites to five, with populations in a 1:1:2:2:1 ratio. These sites are labeled from a to e and the lines were first assigned using the local curvature and the population ratio. ${ }^{10}$ The assignment has been confirmed with a ${ }^{13} \mathrm{C}$ liquid-state NMR 2D refocused INADEQUATE recorded on isotopically enriched $\mathrm{C}_{70} .{ }^{13}$ The $\mathrm{C}_{70}$ molecule with the a-e sites and the quantitative $1 \mathrm{D}{ }^{13} \mathrm{C}$ MAS-NMR spectrum are shown in Figure 1. The results from the fits are provided in Table S2. The longitudinal relaxation time constants $\left(\mathrm{T}_{1}\right)$ are rather small for these compounds (between 1.5 and 3s) and become smaller with increasing $\mathrm{B}_{0}$ strength. This is expected given the large chemical shift anisotropies (CSA) calculated by DFT (190 ppm) for the (static) low-temperature Pbmn structure and the comparatively small values (30-50 ppm) measured at room temperature, where $\mathrm{C}_{70}$ molecules undergo free rotation around the polar axis. ${ }^{21}$ CSA fluctuations are thus expected to be the main source of relaxation, ${ }^{21}$ which are consequently more efficient at higher magnetic fields. It is possible as a result to directly record a natural-abundance ${ }^{13} \mathrm{C}$ spectrum in a short time without crosspolarization for $\mathrm{C}_{70}$.

No ${ }^{1} \mathrm{H}$ or paramagnetic defect is found in the crystallized $\mathrm{C}_{70}$ samples. The loss of coherence is consequently slow (long $\mathrm{T}_{2}$ ), no decoupling is needed, and MAS easily removes the CSA sidebands and is expected to quench any undesired crossterm. ${ }^{35}$ The J-coupling between adjacent ${ }^{13} \mathrm{C}$ spins, around $60 \mathrm{~Hz},{ }^{13}$ is then sufficient to mediate the creation of antiphase coherences between chemically bound ${ }^{13} \mathrm{C}$ pairs and thus to allow acquisition of J-mediated correlation experiments. The optimum refocused INADEQUATE signal was found for conversion and reconversion delays of $8.2 \mathrm{~ms}$ before and after the double-quantum evolution time, which is equal to the theoretical optimum of 
$1 /(2 \mathrm{~J})$, as expected for comparatively long $\mathrm{T}_{2}$.

The 2D refocused INADEQUATE spectra recorded at 7 and $20 \mathrm{~T}$ are shown in Figure $1 \mathrm{C}$ and D. For the first time, these spectra were recorded using nonenriched $\mathrm{C}_{70}$ samples. Whereas a few examples of ${ }^{13} \mathrm{C}-{ }^{13} \mathrm{C}$ correlation spectra collected at natural abundance in the solid state have been reported ${ }^{36}$ (most of which with the refocused INADEQUATE experiment), this is also the first example using direct ${ }^{13} \mathrm{C}$ excitation rather than the ${ }^{13} \mathrm{C}\left\{{ }^{1} \mathrm{H}\right\}$ crosspolarization (CP) classically employed in organic solids. The spectrum obtained at 7 T shows three pairs of cross-peaks, ab, c-d and d-e. The b-c pair of crosspeaks is missing because the frequency separation of $b$ and $c(40 \mathrm{~Hz})$ remains too small as compared to the J-coupling $(60 \mathrm{~Hz})$ inducing strong J-coupling effects, i.e. the J-coupling Hamiltonian $(2 \pi J I S)$ cannot be reduced to $2 \pi J I_{z} S_{Z} \cdot{ }^{22,37}$ In such a case, antiphase terms are not created, and simulations performed with SPINEVOLUTION confirm this result. ${ }^{25}$ The line widths $(\approx 40 \mathrm{~Hz})$ of the ${ }^{13} \mathrm{C}$ lines are small enough to allow direct observation of the ${ }^{2} \mathrm{~J}\left({ }^{13} \mathrm{C}-{ }^{13} \mathrm{C}\right)$ splitting, as illustrated in the corresponding slices (Figure 2). The SPINEVOLUTION simulations accurately reproduce the distortion of the multiplets stemming from the strong J-coupling effect ("roof" effect, shown in Figure 2).

To observe the missing b-c cross-peaks, the frequency separation between $b$ and c lines (in Hz) must be increased, which is easily achieved by using a stronger $\mathrm{B}_{0}$ field. At $20 \mathrm{~T}$, the frequency separation between $b$ and $c(113 \mathrm{~Hz})$ becomes large enough to observe the b-c cross-peaks in the 2D INADEQUATE spectrum (Figure 1D). However, the line widths (resulting from the interplay of J-splitting and chemical shift distribution stemming from structural disorder) become larger $(\approx 150 \mathrm{~Hz}$ full width at half maximum,
FWHM) and the multiplets cannot be observed directly anymore. Correlated disorder effects can even be distinguished from the elongated shapes of the cross-peaks. ${ }^{38}$

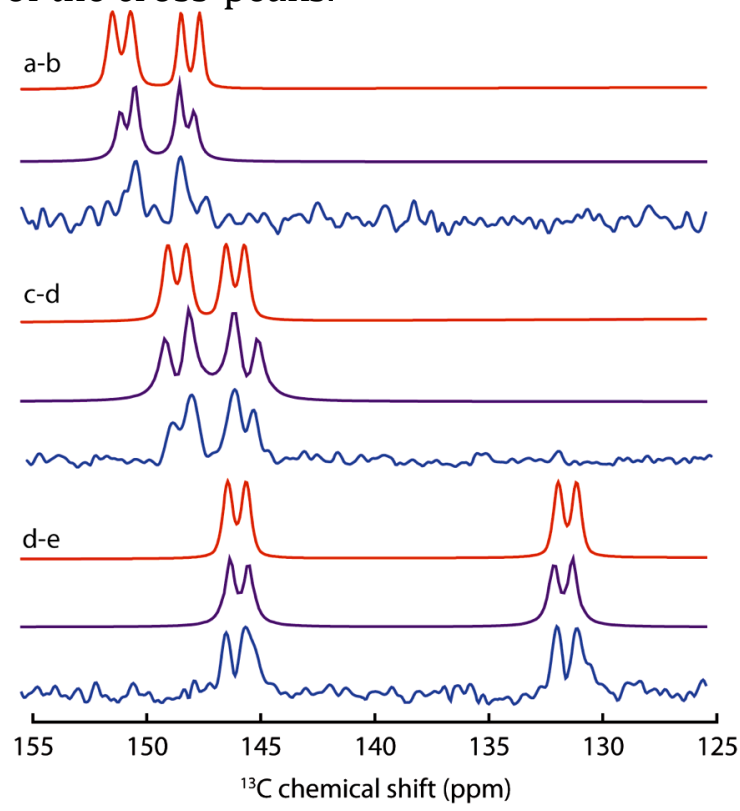

Figure 2. 1D slices of the refocused ${ }^{13} \mathrm{C}$ INADEQUATE spectrum of $\mathrm{C}_{70}$ obtained at $7 \mathrm{~T}$ (blue), for each observed pair of cross-peaks ( $a-b, c-d$ and d-e). The b$c$ pair is not observed because of the strong coupling effect as the spectral separation between b and c $(40 \mathrm{~Hz})$ becomes small and interferes with the Jcoupling $(\approx 60 \mathrm{~Hz})$. The theoretical spectra with no strong J-coupling effect are shown in red (obtained with dmfit24) and the simulated spectra obtained with SPINEVOLUTION ${ }^{25}$ are shown in purple to illustrate the "roof" effect resulting from the strong Jcoupling.

The main interest behind studying $\mathrm{C}_{70}$ lies in its ability to mimic on a small scale the expected structure of nanoporous carbons. ${ }^{39,40}$ The ${ }^{13} \mathrm{C}$ MASNMR spectrum of a supercapacitor electrode made with a nanoporous carbon is compared to the $\mathrm{C}_{70}$ MAS-NMR spectrum in Figure 3. The expected chemical shifts of commonly found moieties are also represented. In the nanoporous carbon, the signals appearing between 140-160 ppm does not correspond to commonly found chemical groups and therefore may indicate $\mathrm{sp}^{2}$ carbons with stronger curvatures, as seen in the $\mathrm{C}_{70} \mathrm{NMR}$ spectrum. 


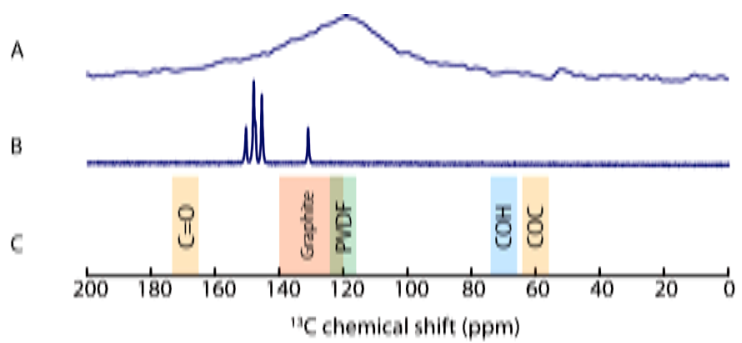

D
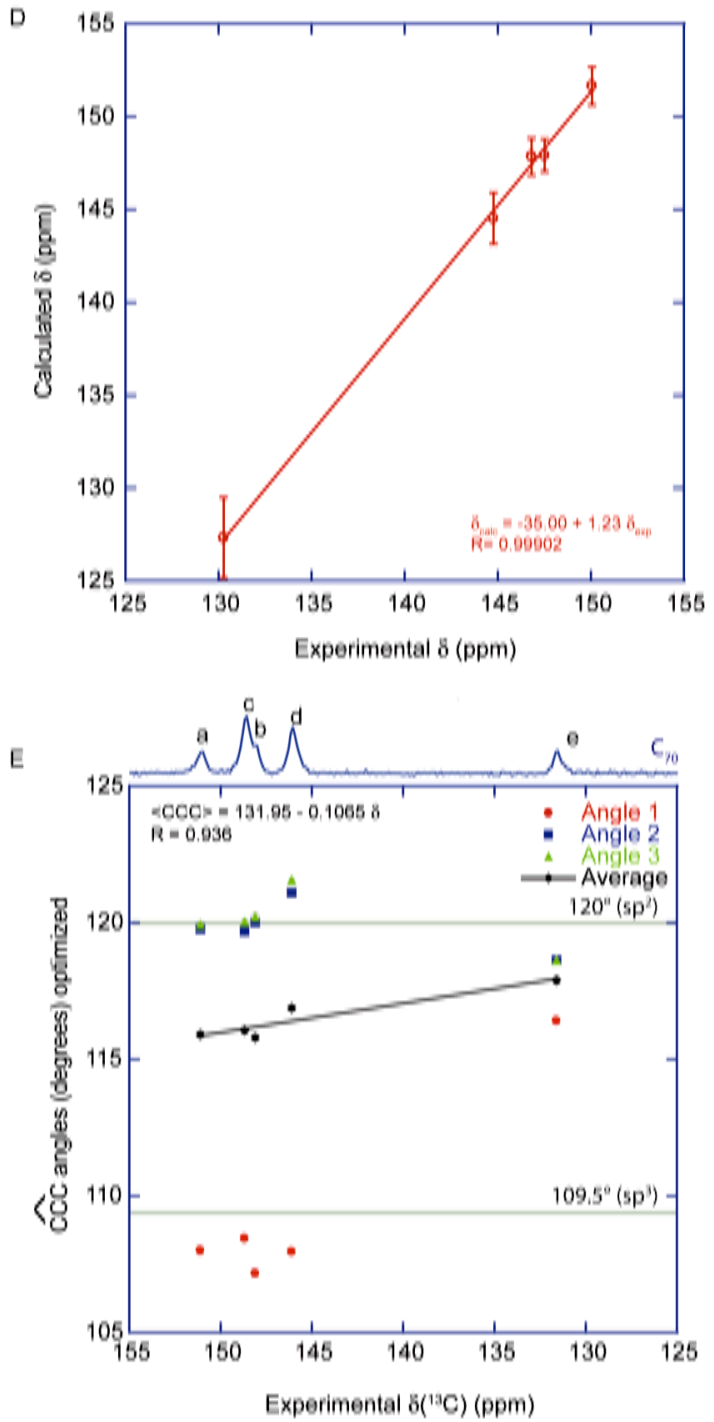

Figure $3 .{ }^{13} \mathrm{C}$ MAS-NMR spectra of a supercapacitor electrode (A) and solid-state $\mathrm{C}_{70}(\mathrm{~B})$ with the expected chemical shift ranges for the commonly found chemical entities (C). , D: Plot of the ${ }^{13} \mathrm{C}$ chemical shifts calculated by DFT (obtained with the lowtemperature $\mathrm{Pbmn}$ structure, in which the $\mathrm{C}_{70}$ molecules do not rotate, as opposed to the roomtemperature behavior ${ }^{21}$ ) vs the experimentally measured ${ }^{13} \mathrm{C}$ shifts. We assumed that the $\mathrm{C}_{70}$ rotation averaged the chemical shifts in each class of a-e atoms, and the error bars represent the standard deviations observed for each set of calculated chemical shifts. E: Plot of the three CCC angles obtained from the DFT-optimized structure and their average as a function of the experimental ${ }^{13} \mathrm{C}$ chemical shifts measured for $\mathrm{C}_{70}$. The error bars correspond to the standard deviations for each set of angles. The green lines indicate the CCC bond angles obtained for $\mathrm{sp}^{2}$ carbons $\left(120^{\circ}\right)$ and $\mathrm{sp}^{3}$ carbons $\left(109.5^{\circ}\right)$.

To understand the origins in terms of local structure of the chemical shift variations in $\mathrm{C}_{70}$, the chemical shifts have also been calculated with DFT. Three cases have been considered: isolated $\mathrm{C}_{70}$ molecules and crystalline $\mathrm{C}_{70}$ with and without the symmetries of the original Pbmn space group of the low-temperature structure. Although the solid-state calculations provide slightly better agreement with the experimental values, the three calculations methods provided chemical shifts with strong linear correlation to the experimental values. Systematic deviations from the perfect 1:1 correlation are not unusual for DFT calculations of NMR parameters. They are most probably accounted for by approximations of the exchangecorrelation functional and, in the presence case, by the comparison of a static model and a strongly dynamic experimental system. The results are provided in the supplementary materials section (Table S3). The values obtained with the immobile $\mathrm{C}_{70}$ molecules in the Pbmn structure have been averaged to reproduce the effect of the molecular rotation about the polar axis. The resulting values are shown in Figure 3, and the standard deviations of the calculated shifts for each type of ${ }^{13} \mathrm{C}$ site are plotted as error bars thus reflecting the spread in chemical shifts expected when the $\mathrm{C}_{70}$ rotation is stopped. One can see that the linear correlation is excellent, with $\mathrm{R}=0.9990$, showing that the DFT calculations are perfectly able to offer an alternate way to assign the ${ }^{13} \mathrm{C}$ resonances. Interestingly, the average shifts calculated for each type of site do not significantly differ when the $\mathrm{C}_{70}$ molecule is considered in isolation (see Supplementary Material, Table S3). The spread of calculated values for each ${ }^{13} \mathrm{C}$ 
site, in contrast, varies considerably between the isolated molecule and the solid-state model. Specifically, calculated shifts are virtually identical of every atom of a given type in isolated $C_{70}$ (standard deviations of 0.01 to 0.03 ppm, see Table S3) and are substantially distributed for crystalline $\mathrm{C}_{70}$ with and without symmetry (standard deviations of 0.8 to $2.0 \mathrm{ppm}$ ). This result clearly indicates that the spread of calculated ${ }^{13} \mathrm{C}$ shifts for static crystalline $\mathrm{C}_{70}$ is entirely due to inter-molecular effects due to ring currents induced by the magnetic field in adjacent $\mathrm{C}_{70}$ molecules. At ambient temperature, fast rotation of the molecules is expected to reduce these effects to zero.

Translating the observed chemical shift values into simple geometric considerations is more difficult, but important trends can nevertheless be obtained based on the combination of experimental NMR and diffraction data and DFT calculations.As shown in Figure $3 \mathrm{E}$, for each carbon in $\mathrm{C}_{70}$, the three CCC bond angles (obtained from the DFToptimized structure) can be divided into two groups: two large angles with values close to $120^{\circ}$, which correspond to the typical angles observed for $\mathrm{sp}^{2}$ carbons, and one smaller angle, close to $109^{\circ}$, which is close to the CCC angle observed for $\mathrm{sp}^{3}$ carbons. Therefore, we may expect activated carbons to have similar behaviors for the CCC bond angles, where the curvature of graphene layer is achieved with similar bond angles variations by including five-members rings among the network of 6-members rings.

The best linear correlation we found was between the average of the three CCC angles and the ${ }^{13} \mathrm{C}$ chemical shift of the carbon atom in the center. The correlation obtained between the experimental shifts and the CCC angles obtained from XRD, CCC $=131.0-0.100$ $\delta$, is quite $\operatorname{good}(R=0.916$, see Figure
S4A from the Supplementary Materials). Furthermore, this correlation improves with the angles obtained from the DFToptimized structure: CCC $=131.95$ $0.1065 \delta$, with $\mathrm{R}=0.936$ (Figure 3E). It is a common finding that, for crystal structures obtained with powder diffraction rather than on single crystals, the precision of atomic positions, and -as a result- of calculated NMR parameters, can be significantly improved by a DFT minimization with fixed unit cell parameters ${ }^{41}$. In this case the variations in atomic positions between the powder XRD and the DFT-optimized structure are small (RMSD of $0.051 \AA$ ), but nevertheless sufficient to improve the trend between experimental NMR results and structural features. Finally, further improvement of the correlation is obtained when considering calculated rather than experimental chemical shifts and the average CCC angles from the DFT-optimized structure: CCC $=129.4$ $0.087 \delta$, with $\mathrm{R}=0.946$ (Figure S4B from the Supplementary Materials). This improvement may be primarily due to a compensation of small residual errors on the atomic positions as minimized by DFT. In the three cases, some discrepancies are observed and must result from other effects which have not been accounted for. Nonetheless, using this linear correlation, one can assume that the chemical shift range between 120 and 160 ppm corresponds to average CCC angles between 119.2 and $114.9^{\circ}$. It is also interesting to notice that the deviation from the planar $\mathrm{sp}^{2}$ carbons found in $\mathrm{C}_{70}$ remains quite small, with only one angle expected to deviate significantly from $120^{\circ}$.

\section{Conclusion}

Carbon materials are now used in supercapacitors, graphite electrodes in batteries, and hybrid systems, "supercapattery", try to take advantage of the best of the two worlds. Therefore, 
with nanotubes, graphene and graphite oxide, elaborated carbon compounds have a bright future ahead in the search for better energy storage strategies. In this paper, we show that natural abundance ${ }^{13} \mathrm{C}$ correlation spectra can be recorded owing to the short longitudinal relaxation times of ${ }^{13} \mathrm{C}$ in $\mathrm{C}_{70}$. A similar effect may be expected in some of the more complex carbon materials, either because of the CSA induced relaxation, or due to the presence of paramagnetic centers. Moreover, experimental chemical shifts can be reproduced with a reasonable accuracy using DFT, and the ${ }^{13} \mathrm{C}$ chemical shift may be translated in terms of average CCC bond angles, offering a plausible interpretation of the ${ }^{13} \mathrm{C}$ MAS-NMR spectra of activated carbons in terms of deviations of graphene layers from planarity.

\section{Acknowledgements}

For DFT calculations, we thank the "Centre de Calcul Scientifique en region Centre" (Orléans, France). 


\section{Supplementary materials}

Table S1. Description of pseudopotential used for planewave-based DFT calculations.

\begin{tabular}{llllllll}
\hline Atom & Core-states & $\begin{array}{l}\text { Local } \\
\text { channel }\end{array}$ & $\begin{array}{l}\boldsymbol{r}_{\text {loc }} \\
\text { (a.u.) }\end{array}$ & $\begin{array}{l}\boldsymbol{r}_{\text {nonloc }} \\
\text { (a.u.) }\end{array}$ & $\begin{array}{l}\boldsymbol{r}_{\text {aug }} \\
\text { (a.u.) }\end{array}$ & $\begin{array}{l}\text { Pseudopotential } \\
\text { projectors }\end{array}$ & PAW projectors \\
\hline $\mathrm{C}$ & $\mathrm{1s}$ & $\mathrm{D}$ & 1.4 & 1.4 & 1.3 & $2 \mathrm{x} 2 \mathrm{~s}, 2 \mathrm{x} 2 \mathrm{p}$ & $2 \times 2 \mathrm{~s}, 2 \times 2 \mathrm{p}$ \\
\hline
\end{tabular}

Where $r_{l o c}$ is the pseudisation radius for the local component of the pseudopotential, $r_{\text {nonloc }}$ is the pseudisation radius for the non-local components of the pseudopotential, and $r_{\text {aug }}$ is the pseudisation radius for the charge augmentation functions.

The corresponding castep on-the-fly string used to generate these potentials is: C $2|1.4| 1.4|1.3| 6|10| 12 \mid 20: 21$ (qc=6)

Table S2. Results from the fit of the 1D NMR spectra.

\begin{tabular}{c|cccc}
\hline Site & $\delta(\mathrm{ppm})$ & $\begin{array}{c}\text { Width (Hz) } \\
\text { @850MHz }\end{array}$ & $\begin{array}{c}\text { Width (Hz) } \\
\text { @300MHz }\end{array}$ & $\begin{array}{c}\text { Area } \\
(\%)\end{array}$ \\
\hline $\mathrm{a}$ & 151.1 & 137 & 39 & $14 \%$ \\
$\mathrm{~b}$ & 148.1 & 135 & 40 & $31 \%$ \\
$\mathrm{c}$ & 148.7 & 135 & 41 & $15 \%$ \\
$\mathrm{~d}$ & 146.1 & 137 & 42 & $28 \%$ \\
$\mathrm{e}$ & 131.6 & 124 & 40 & $12 \%$ \\
\hline
\end{tabular}

Table S3. Chemical shifts obtained by DFT.

\begin{tabular}{|c|c|c|c|c|c|c|c|}
\hline Site & $\begin{array}{c}\text { Average } \delta \\
\text { (ppm) } \\
\text { Isolated } C_{70}\end{array}$ & $\begin{array}{c}\text { StDev } \\
\text { (ppm) } \\
\text { Isolated } \\
C_{70}\end{array}$ & $\begin{array}{c}\text { Average } \delta \\
\text { (ppm) } \\
\text { P1 C } 70\end{array}$ & $\begin{array}{l}\text { StDev } \\
\text { (ppm) } \\
\text { P1 C } 70\end{array}$ & $\begin{array}{c}\text { Average } \delta \\
\text { (ppm) } \\
\text { Pbmn } C_{70}\end{array}$ & $\begin{array}{c}\text { StDev } \\
\text { (ppm) } \\
\text { Pbmn C }_{70}\end{array}$ & Multiplicity \\
\hline$a$ & 151.58 & 0.02 & 151.64 & 0.87 & 151.65 & 0.89 & 10 \\
\hline $\mathrm{b}$ & 146.61 & 0.01 & 147.85 & 0.86 & 147.85 & 0.86 & 10 \\
\hline c & 148.25 & 0.02 & 147.93 & 0.74 & 147.92 & 0.75 & 20 \\
\hline$d$ & 145.13 & 0.03 & 144.52 & 1.26 & 144.52 & 1.25 & 20 \\
\hline $\mathrm{e}$ & 126.79 & 0.02 & 127.31 & 2.02 & 127.32 & 2.03 & 10 \\
\hline
\end{tabular}




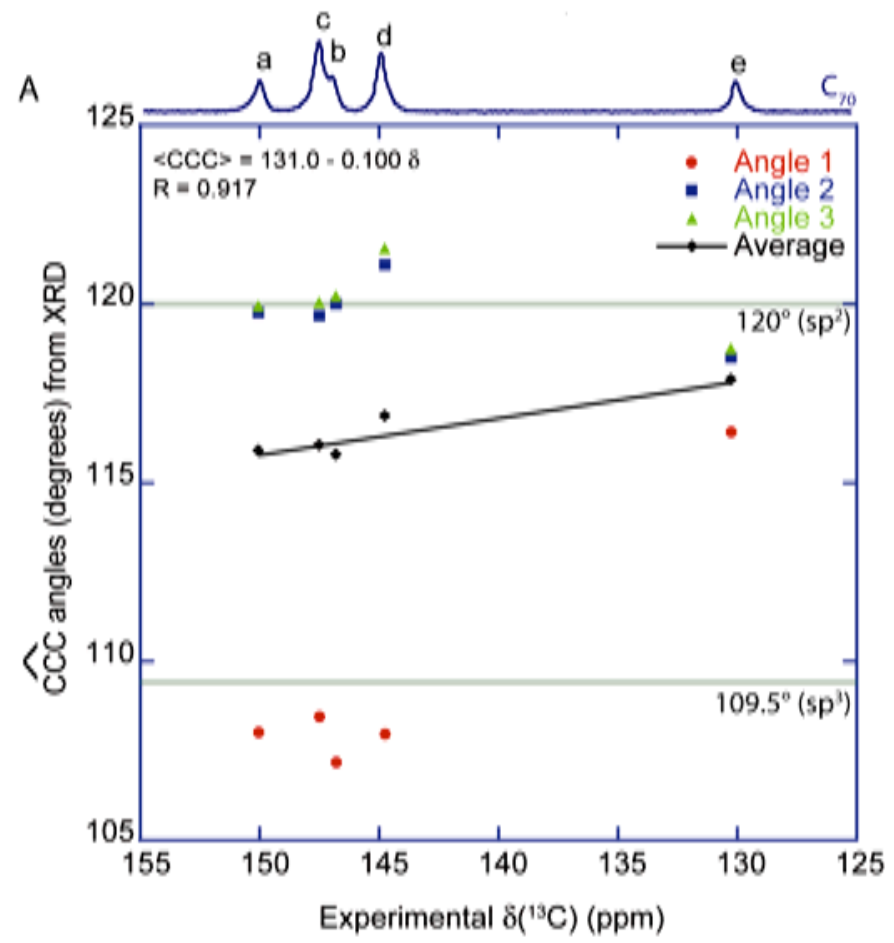

B

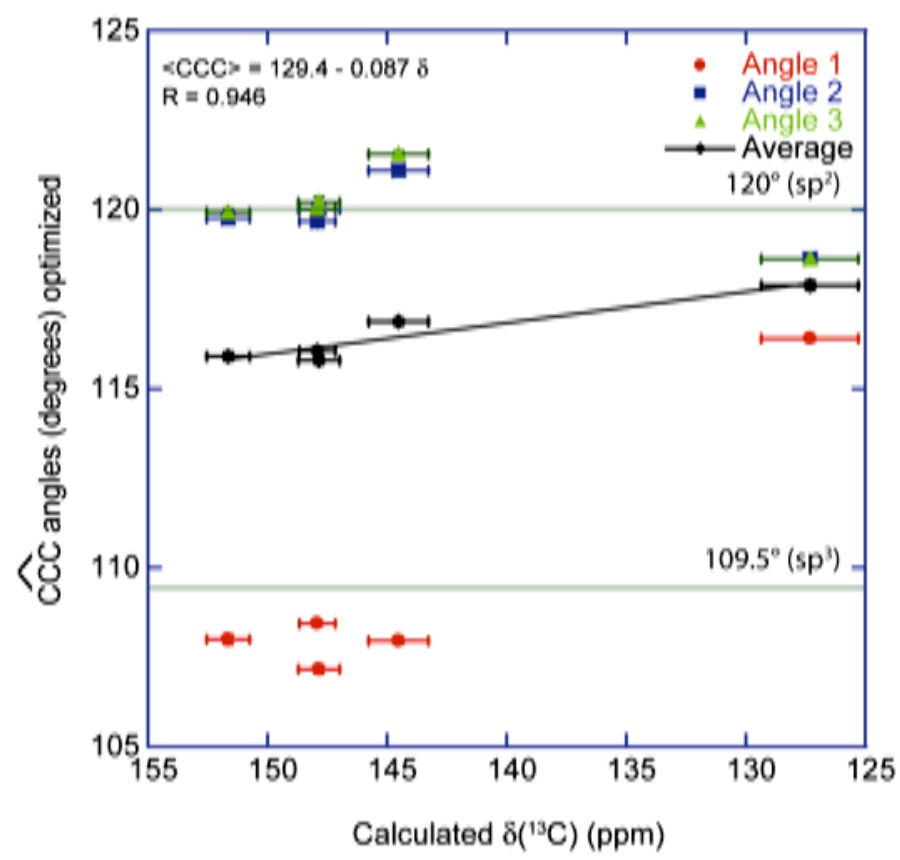

Figure S4. A: Plot of the three CCC angles obtained from the XRD structure and their average as a function of the experimental ${ }^{13} \mathrm{C}$ chemical shifts measured for $\mathrm{C}_{70}$. The green lines indicate the CCC bond angles obtained for $\mathrm{sp}^{2}$ carbons $\left(120^{\circ}\right)$ and $\mathrm{sp}^{3}$ carbons $\left(109.5^{\circ}\right)$. B: Same graph with the ${ }^{13} \mathrm{C}$ chemical shifts calculated with the DFT. The horizontal error bars correspond to the standard deviations for each set of chemical shifts from the a-e sites. The vertical bars are very small and correspond to the standard deviations obtained for each set of CCC angles. 


\section{References}

1 C.Liu, Z.Yu, D.Neff, A.Zhamu, B.Z.Jang, «Graphene-Based Supercapacitor with an Ultrahigh Energy Density », Nano Lett. 10, 4863-4868 (2010)

2 Y.Zhu, S.Murali, M.D.Stoller, K.J.Ganesh, W.Cai, P.J.Ferreira, A.Pirkle, R.M.Wallace, K.A.Cychosz, M.Thommes, D.Su, E.A.Stach, R.S.Ruoff, «Carbon-Based Supercapacitors Produced by Activation of Graphene », Science 332, 1537-1541 (2011).

3 J.J.Yoo, K.Balakrishnan, J.Huang, V.Meunier, B.G.Sumpter, A.Srivastava, M.Conway, A.Leela Mohana Reddy, J.Yu, R.Vajtai, P.M.Ajayan, «Ultrathin Planar Graphene Supercapacitors », NanoLet. 11, 1423-1427 (2011).

4 J.R.Miller, R.A.Outlaw, B.C.Holloway, «Graphene Double-Layer Capacitor with ac Line-Filtering Performance », Science 329, 1637 (2010).

5 C.Niu, E.K.Sichel, R.Hoch, D.Moy, H.Tennent, « High power electrochemical capacitors based on carbon nanotube electrodes », Appl. Phys. Lett. 70, 1480 (1997).

${ }^{6}$ E.Frackowiak, K.Metenier, V.Bertagna, F.Béguin, «Supercapacitor electrodes from multiwalled carbon nanotubes », Appl. Phys. Lett. 77, 2421 (2000).

7 D.N.Futaba, K.Hata, T.Yamada, T.Hiraoka, Y.Hayamizu, Y.Kakudate, O.Tanaike, H.Hatori, M.Yumura, S.Iijima, "Shape-engineerable and highly densely packed single-walled carbon nanotubes and their application as supercapacitor electrodes », Nature Mater. 5, 987 - 994 (2006).

8 A.Izadi-Najafabadi, S.Yasuda, K.Kobashi, T.Yamada, D.N.Futaba, H.Hatori, M.Yumura, S.Iijima, K.Hata, «Extracting the Full Potential of Single-Walled Carbon Nanotubes as Durable Supercapacitor Electrodes Operable at 4 V with High Power and Energy Density », Advanced Mater. 22, E235 (2010).

${ }_{9}^{9}$ T.Sternfeld, R.E.Hoffman, I.Aprahamian, M.Rabinovitz, « Fullerene anions: Unusual charge distribution in $\mathrm{C}_{70}{ }^{6-}$. » Angew. Chem. Int. Ed. 40, 455-457 (2001).

10 R.Taylor, J.P.Hare, A.K.Abdul-Sada, H.W.Kroto, «Isolation, Separation and Characterisation of the Fullerenes $\mathrm{C}_{60}$ and $\mathrm{C}_{70}$ : The Third Form of Carbon », Chem. Commun., 1423 (1990).

11 R.C.Haddon, "Chemistry of the Fullerenes: The Manifestation of Strain in a Class of Continuous Aromatic Molecules », Science 261, 1545-1550 (1993).

12 C.A.Reed, K.-C.Kim, R.D.Bolskar, L.J.Mueller, « Taming Superacids: Stabilization of the Fullerene Cations $\mathrm{HC}^{+} 0^{+}$and $\mathrm{C}_{60^{+}}{ }^{\prime}$, Science 289, 101 (2000).

13 R.D.Johnson, G.Meijer, J.R.Salem, D.S.Bethune, «2D Nuclear Magnetic Resonance Study of the Structure of the Fullerene $C_{70}$ », J. Am. Chem. Soc. 113, 3619-3621 (1991).

14 M.Bühl, W.Thiel, H.Jiao, P.von Ragué Schleyer, M.Saunders, F.A.L.Anet, « Helium and Lithium NMR Chemical Shifts of Endohedral Fullerene Compounds: An ab Initio Study »

J. Am. Chem. Soc. 116, 6005-6006 (1994).

15 M.S.Meier, H.P.Spielmann, R.G.Bergosh, R.C.Haddon, "A ${ }^{13} \mathrm{C}$ INADEQUATE and HF-GIAO Study of $\mathrm{C}_{60} \mathrm{H}_{2}$ and $\mathrm{C}_{60} \mathrm{H}_{6}$ Identification of Ring Currents in a 1,2-Dihydrofullerene", J. Am. Chem. Soc. 124, 8090-8094 (2002).

16 F.H.Hennrich, R.H.Michel, A.Fischer, S.Richard-Schneider, S.Gilb, M.M.Kappes, D.Fuchs, M.Bürk, K.Kobayashi, S.Nagase, "Isolation and Characterization of $\mathrm{C}_{80}$ », Angew. Chem. Int. Ed. 35, 1732-1734 (1996).

17 M.Saunders, H.A.Jiménez-Vázquez, R.J.Cross, S.Mroczkowski, D.I.Freedberg, F.A.L.Anet, « Probing the interior of fullerenes by ${ }^{3} \mathrm{He} N \mathrm{NR}$ spectroscopy of endohedral ${ }^{3} \mathrm{He} @ \mathrm{C}_{60}$ and ${ }^{3} \mathrm{He} @ \mathrm{C}_{70}$ », Nature 367, 256258 (1994).

18 T.Sternfeld, M.Saunders, R.J.Cross, M.Rabinovitz, «The Inside Story of Fullerene Anions: A ${ }^{3} \mathrm{He}$ NMR Aromaticity Probe », Angew. Chem. Int. Ed. 42, 3136 - 3139 (2003).

19 T.Sternfeld, R.E.Hoffman, C.Thilgen, F.Diederich, M.Rabinovitz, «Reduction of Fulleroids $\mathrm{C}_{71} \mathrm{H}_{2}$ : $\mathrm{Probing}$ the Magnetic Properties of $\mathrm{C}_{70^{6-}} »$, J. Am. Chem. Soc. 122, 9038-9039 (2000).

20 W.Kolodziejski, J.Klinowski, ${ }^{13} \mathrm{C}-{ }^{-1} \mathrm{H}$ and ${ }^{1} \mathrm{H}-{ }^{13} \mathrm{C}$ cross-polarization NMR in toluene-solvated fullerene70 », Chem. Phys. Lett. 247, 507-509 (1995).

${ }^{21}$ L.Firtej, Z.Belahmer, P.Bernier, A.Zahab, M.Ribet, N.Coustel, R.Aznar, « Molecular Motion in Solid $\mathrm{C}_{70}$ by ${ }^{13} \mathrm{C}$ High-Resolution NMR », Solid State Commun. 87, 669-673 (1993).

${ }^{22}$ A.Bax, R.Freeman, "Investigation of ${ }^{13} \mathrm{C}-{ }^{13} \mathrm{C}$ Couplings in Natural Abundance Samples: The Strong Coupling Case”, J. Magn. Reson. 41, 507-511 (1980).

23 (a) C.A. Fyfe, H. Grondey, Y. Feng, G.T. Kokotailo, "Natural-Abundance 2-Dimensional ${ }^{29}$ Si MAS NMR investigation of the 3-dimensional bonding connectivities in the zeolite catalyst ZSM-5", J. Am. Chem. Soc. 112, 8812-8820 (1990), (b) A. Lesage, C. Auger, S. Caldarelli, L. Emsley, "Determination of through-bond carbon-carbon connectivities in solid-state NMR using the INADEQUATE experiment”, J. Am. Chem. Soc. 119, 7867-7868 (1997). 
24 D.Massiot, F.Fayon, M.Capron, I.King, S.Le Calvé, B.Alonso, J.O.Durand, B.Bujoli, Z.Gan, G.Hoatson, "Modelling one and two-dimensional solid-state NMR spectra", Magn. Reson. Chem. 40, 70-76 (2002).

${ }^{25}$ M.Veshtort, R.G.Griffin, "SPINEVOLUTION: A powerful tool for the simulation of solid and liquid state NMR experiments”, J. Magn. Reson. 178, 248-282 (2006).

${ }^{26}$ M.D.Segall, P.J.D.Lindan, M.J.Probert, C.J.Pickard, P.J.Hasnip, S.J.Clark, M.C.Payne,

«First-principles simulation: ideas, illustrations and the CASTEP code », J. Phys.: Condens. Matter 14, 27172744 (2002).

27 S.J.Clark, M.D.Segall, C.J.Pickard, P.J.Hasnip, M.J.Probert, K.Refson, M.C.Payne, «First principles methods using CASTEP », Z. Kristallogr. 220, 567-570 (2005).

${ }^{28}$ J.P.Perdew, K.Burke, M.Ernzerhof, « Generalized Gradient Approximation Made Simple », Phys. Rev. Lett. 77, 3865-3868 (1996).

${ }^{29}$ D.Vanderbilt, « Soft self-consistent pseudopotentials in a generalized eigenvalue formalism », Phys. Rev. B 41, 7892-7895 (1990).

30 A.Tkatchenko, M.Scheffler, «Accurate Molecular Van Der Waals Interactions from Ground-State Electron Density and Free-Atom Reference Data », Phys. Rev. Lett. 102, 073005 (2009).

31 C.J.Pickard, F.Mauri, "All-electron magnetic response with pseudopotentials: NMR chemical shifts », Phys. Rev. B 63, 245101 (2001).

32 J.R.Yates, C.J.Pickard, F.Mauri, « Calculation of NMR chemical shifts for extended systems using ultrasoft pseudopotentials », Phys. Rev. B 76, 024401 (2007).

${ }^{33}$ S.van Smaalen, V.Petricek, J.L.de Boer, M.Dusek, M.A.Verheijen, G.Meijer, « Low-temperature structure of solid $\mathrm{C}_{70}$ », Chem. Phys. Lett. 223, 323-328 (1994).

34 H.J.Monkhorst, J.D.Pack, «Special points for Brillouin-zone integrations », Phys. Rev. B 13, 5188-5192 (1976).

35 F.Fayon, D.Massiot, M.H.Levitt, J.J.Titman, D.H.Gregory, L.Duma, L.Emsley, S.P.Brown, “Through-space contributions to two-dimensional double-quantum J correlation NMR spectra of magic-angle-spinning solids", J. Chem. Phys. 122, 194313 (2005).

${ }^{36}$ (a) R.A.Olsen, J.Struppe,D.W.Elliott, R.J.Thomas, L.J.Mueller,"Through-Bond ${ }^{13} \mathrm{C}-{ }^{13} \mathrm{C}$ Correlation at the Natural Abundance Level: Refining Dynamic Regions in the Crystal Structure of Vitamin-D ${ }_{3}$ with SolidState NMR”, J. Am. Chem. Soc. 125, 11784-11785 (2003) ; (b) H.Kono, T.Erata, M.Takai, “Determination of the Through-Bond Carbon-Carbon and Carbon-Proton Connectivities of the Native Celluloses in the Solid State", Macromolecules 36, 5131-5138 (2003); (c) G. De Paëpe, A.Lesage, S.Steuernagel, L.Emsley, "Transverse dephasing optimised NMR spectroscopy in solids: Natural-abundance ${ }^{13} \mathrm{C}$ correlation spectra", ChemPhysChem 5, 869-875 (2004) ; (d) R.K.Harris, S.A.Joyce, C.J.Pickard, S.Cadars, L.Emsley, "Assigning carbon-13 NMR spectra to crystal structures by the INADEQUATE pulse sequence and first principles computation: a case study of two forms of testosterone", Phys. Chem. Chem. Phys. 8, 137-143 (2006) ; (e) R.K.Harris, S.Cadars, L.Emsley, J.R.Yates, C.J.Pickard, R.K.R.Jetti, U.J.Griesser, "NMR crystallography of oxybuprocaine hydrochloride, Modification II", Phys. Chem. Chem. Phys. 9, 360 - 368 (2007).

${ }^{37}$ M.H.Levitt, “Spin Dynamics. Basics of Nuclear Magnetic Resonance.”, Wiley, Chichester, England (2001).

38 S.Cadars, A.Lesage, L.Emsley, "Chemical Shift Correlations in Disordered Solids", J. Am. Chem. Soc. 127, 4466-4476 (2005).

39 P.J.F.Harris, "New Perspectives on the Structure of Graphitic Carbons", Critical Reviews in Solid State and Materials Sciences 30, 235 (2005).

${ }^{40}$ A.Kumar, R.F.Lobo, N.J.Wagner, "Porous amorphous carbon models from periodic Gaussian chains of amorphous polymers", Carbon 43, 3099-3111 (2005).

${ }^{41}$ R.K. Harris, P. Hodgkinson, C.J. Pickard, J.R. Yates, V. Zorin, “Chemical shift computations on a crystallographic basis: some reflections and comments”, Magn. Reson. Chem. 45, S174-S186 (2007). 